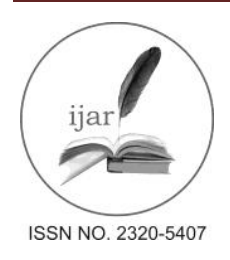

Journal homepage: http://www.journalijar.com

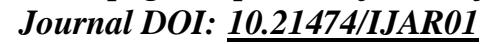

INTERNATIONAL JOURNAL

OF ADVANCED RESEARCH

RESEARCH ARTICLE

\title{
APPLICATION OF DIGITAL SIGNAL PROCESSORS IN AUTOMOBILES.
}

\begin{abstract}
*Anamika.
Department of Mechatronics, Manipal Institute of Technology.
\end{abstract}

\begin{abstract}
Manuscript Info
Manuscript History:

Received: 14 April 2016

Final Accepted: 19 May 2016

Published Online: June 2016

Key words:

Cars, automobile, DSP, ISA, EPAS,

motors, Texas Instruments, CAN

bus.

*.....................

Anamika.

Abstract

Automobiles are undergoing digital makeover. Today's automobile is a Digital automobile, incorporating dozens of embedded processor connected Via multiple digital networks ,controlling and optimizing the operations.

\section{Introduction:-}

In today's Automobile Industry electric power assisted steering (EPAS) and integrated starter alternator (ISA) are used widely. When using a hydraulic steering system, hydraulic pump and hydraulic pistons are used to make the steering work. Due to which the engine experieneses a sudden force. This was further removed by using electromechanical design in which electric motors were used to produce torque by the steering which reduced the force on engine.
\end{abstract}

\section{Application of DSP:-}

Electromechanical steering assist (ESA) also improve the reliability of vehicle. Permanent magnet synchronous motors are generally used to generate the steering assist torque. The system consists of two vital components: Torque Sensor and EPAS Controller (a component of digital signal controller). The torque sensor senses the torque direction applied by the driver; it is then fed to an amplifier with a gain determined by the speed. At low speed, maximum assist is provided while at high speed the assistant decreases. The EPAS controller gets the vehicle speed information from one of the other control modules in the car, such as Engine Control Module, Controller Area Network (CAN) bus. The EPAS controller then translates this to a torque command to a motor control algorithm. Digital signal processor based controller are enabling automotive manufacturers to design their EPAS and ISA controller module with advanced techniques such as field -oriented control to overcome the traditional implementation challenges.

\section{Result and Discussion:-}

Modern motor control-specific DSP controllers like MIPS TMS320F2812 digital signal controllers are designed with key motor controllers. Among these are on chip flash memory, A/D convertors, Pulse Width Modulation (PWM) outputs and can bus controllers. DSP can help cut vehicle weight, save costs, reduce gas consumption and exhaust emission and improve the travel experience for drivers and passengers alike.

\section{References:-}

1. Stranneby Dag (2001).Digital signal processing fundamentals Sci. 58: 171-182.

2. Smith W. Steven (1997). The scientist's and engineer's guide to Digital Signal ProcessingSci. 57:47-50.

3. Ingle Vinay K. ,Proakis John G. (2011) Digital signal processing in automobile industries Sci. 57:47-50. 